University of Nebraska - Lincoln

DigitalCommons@University of Nebraska - Lincoln

Faculty Papers and Publications in Animal

Science

Animal Science Department

2-18-2003

\title{
Estimates of genetic parameters and genetic change for reproduction, weight, and wool characteristics of Targhee sheep
}

\author{
Kathryn J. Hanford \\ University of Nebraska, kathy.hanford@unl.edu \\ L. Dale Van Vleck \\ University of Nebraska-Lincoln, dvan-vleck1@unl.edu \\ G. D. Snowder \\ USDA, ARS, U.S. Sheep Experimental Station, Dubois, ID
}

Follow this and additional works at: https://digitalcommons.unl.edu/animalscifacpub

Part of the Animal Sciences Commons

Hanford, Kathryn J.; Van Vleck, L. Dale; and Snowder, G. D., "Estimates of genetic parameters and genetic change for reproduction, weight, and wool characteristics of Targhee sheep" (2003). Faculty Papers and Publications in Animal Science. 197.

https://digitalcommons.unl.edu/animalscifacpub/197

This Article is brought to you for free and open access by the Animal Science Department at DigitalCommons@University of Nebraska - Lincoln. It has been accepted for inclusion in Faculty Papers and Publications in Animal Science by an authorized administrator of DigitalCommons@University of Nebraska - Lincoln. 


\title{
Estimates of genetic parameters and genetic change for reproduction, weight, and wool characteristics of Targhee sheep ${ }^{1}$
}

\author{
K. J. Hanford ${ }^{* 2}$, L. D. Van Vleck $\uparrow$, and G. D. Snowder $\neq^{3}$ \\ *Department of Animal Science, University of Nebraska, Lincoln 68583-0908; †USDA, ARS, \\ U.S. Meat Animal Research Center, Lincoln, NE 68583-0908; and \\ †USDA, ARS, U.S. Sheep Experimental Station, Dubois, ID 83423
}

\begin{abstract}
Genetic parameters from both singletrait and bivariate analyses for prolificacy, weight, and wool traits were estimated using REML with animal models for Targhee sheep from data collected from 1950 to 1998 at the U.S. Sheep Experiment Station, Dubois, ID. Breeding values from both single-trait and seventrait analyses calculated with the parameters estimated from the single-trait and bivariate analyses were compared across years of birth with respect to genetic trends. The numbers of observations were 38,625 for litter size at birth and litter size at weaning, 33,994 for birth weight, 32,715 for weaning weight, 36,807 for fleece weight and fleece grade, and 3,341 for staple length. Direct heritability estimates from single-trait analyses were 0.10 for litter size at birth, 0.07 for litter size at weaning, 0.25 for birth weight, 0.22 for weaning weight, 0.54 for fleece weight, 0.41 for fleece grade, and 0.65 for staple length. Estimate of direct genetic correlation between litter size at birth and weaning was 0.77 and between birth and weaning weights was 0.52 . The estimate of genetic correlation between fleece weight and staple length was positive (0.54), but was negative between fleece weight and fleece grade $(-0.47)$
\end{abstract}

and between staple length and fleece grade $(-0.69)$. Estimates of genetic correlations were near zero between birth weight and litter size traits and small and positive between weaning weight and litter size traits. Fleece weight was slightly and negatively correlated with both litter size traits. Fleece grade was slightly and positively correlated with both litter size traits. Estimates of correlations between staple length and litter size at birth (-0.14) and litter size at weaning (0.05) were small. Estimates of correlations between weight traits and fleece weight were positive and low to moderate. Estimates of correlations between weight traits and fleece grade were negative and small, whereas estimates between weight traits and staple length were positive and small. Estimated breeding values averaged by year of birth from both the single- and seven-trait analyses for the prolificacy and weight traits increased over time, whereas those for fleece weight decreased slightly and those for the other wool traits were unchanged. Estimated changes in breeding values over time did not differ substantially for the single-trait and seven-trait analyses, except for traits highly correlated with another trait that was responding to selection.

Key Words: Breeding Value, Genetic Correlation, Heritability, Litter Size, Prolificacy, Weaning Weight

(C2003 American Society of Animal Science. All rights reserved.

J. Anim. Sci. 2003. 81:630-640

\section{Introduction}

Few selection studies have been conducted with dualpurpose Western range sheep in the United States, and even fewer of these can be considered long-term studies. Sakul et al. (1999) reported slight improvement in litter

\footnotetext{
${ }^{1}$ Published as paper No.13811, Journal Ser., Nebraska Agric. Res. Div., Univ. of Nebraska, Lincoln 68583-0908.

${ }^{2}$ Correspondence: A218 Animal Science (phone: 402-472-6409; fax: 402-472-6362; E-mail: khanford2@unl.edu).

${ }^{3}$ Current address: Roman L. Hruska U.S. Meat Animal Research Center, Clay Center, NE 68933-0166.

Received August 27, 2002.

Accepted November 22, 2002.
}

size and 120-d weight over a 30-yr period for Targhee sheep in a range environment. However, they concluded that the response represented a potentially significant economic advantage. Ercanbrack and Knight (1998) reported phenotypic trends and genetic gains for a 12-yr period for four breeds of range sheep. They showed that selection solely for litter weight of weaned lambs substantially increased lamb production with only minor penalties in wool production. Burfening et al. (1993) estimated genetic change in reproductive rate in Rambouillet sheep raised in a range environment with selection for $18 \mathrm{yr}$ based on a reproductive index of dam's total lifetime lambs born. Their results indicated that use of the reproductive index led to a favorable response to selection. Lasslo et al. (1985) reported genetic improvement in Targhee sheep selected for weaning 
weight over $20 \mathrm{yr}$ for both a range environment and an environment with a higher plane of nutrition. Results from analyses of Columbia sheep selected concurrently with the Targhee sheep summarized in this paper were presented by Hanford et al. (2002) and indicated that Columbia sheep responded favorably to selection for weaning performance.

The main objective of this study was to document genetic trends in production traits of the Targhee breed at the U.S. Sheep Experiment Station (USSES), Dubois, ID, over a 49-yr period (1950 to 1998), where selection was based on weaning performance under range conditions. The production traits examined included prolificacy, weight, and wool traits. A secondary objective was to compare genetic trends estimated from singleand seven-trait analyses.

\section{Materials and Methods}

\section{Animals and Management}

The Targhee breed, a dual-purpose breed of sheep, was developed at the USSES beginning in 1926 from ewes of Corriedale by Lincoln-Rambouillet and Lincoln $\times$ Rambouillet crosses mated to Rambouillet rams. Descendants of these crosses were then interbred and carefully selected to produce Targhee sheep (Terrill, 1947). From its inception, the Targhee breed has been maintained and included in a variety of selection projects at the USSES (Ercanbrack and Knight, 1981; 1998). The USSES has been a primary source of foundation breeding stock for the Targhee breed. This population of Targhee sheep represents the longest time span (49 yr) and the largest number of animals (approximately 34,000 lamb records) currently available for determining genetic parameters for the Targhee breed. Currently, few estimates of genetic parameters for the Targhee breed are available. Bromley et al. (2000) estimated genetic parameters using data collected from 1977 to 1996 from this population.

During the 49-yr period (1950 to 1998), the Targhee breed at USSES was subjected to different selection criteria, all generally related to increasing weaning weight. Selection favored wool and growth traits in the early years (approximately 1950 to 1969), then individual lamb weaning weight and litter size (from 1969 to 1976), and finally weaning weight of the lamb or total litter weight weaned of the ewe (from 1976 to 1998). A random-bred control line was also maintained for many of these years. A total of six outside rams were introduced, all for the 1989 through 1991 breeding seasons. Lines have been rerandomized several times as new selection criteria were imposed on the flock. Rams in control lines that were superior for the selection traits were often used in the appropriate selection lines. The effects of specific selection objectives could not be accounted for because of the rerandomization of breeding animals over the years of this study. The genetic trend in this flock, however, may represent general, but changing, selection emphases of the American sheep industry over this time period.

The numbers of records per trait, as well as unadjusted means and standard deviations, are presented in Table 1. Ercanbrack and Knight (1998) and Hanford et al. (2002) previously described management of the flock.

Prolificacy Traits. Litter sizes at birth (number of lambs born per ewe exposed in single-sire pen matings) and at weaning (number of lambs weaned per ewe exposed) were recorded for each ewe exposed and present at lambing. Only lambs born and raised by a ewe were included in litter size at weaning. A summary of the numbers of litters born, types of birth, and survival by type of birth is presented in Table 2. Lower survival rates of single-born lambs compared to twin-born lambs were likely due to the greater proportion of single born lambs being reared by younger ewes (Snowder et al., 2001). A summary of numbers of ewes by age, litter size at both birth and weaning, and survival by age of ewe is presented in Table 3.

Weight Traits. Birth weight (kg) was recorded for all lambs born alive. Only records from purebred lambs raised by their birth dam were included in analyses of weaning weight data. Weaning weight $(\mathrm{kg})$ was adjusted to $120 \mathrm{~d}$ of age using individual birth weight and average daily gain from birth to weaning.

Wool Traits. Greasy fleece weight $(\mathrm{kg})$ and fleece grade (U.S. spinning count) were obtained annually at shearing in late May. Fleece grades were subjectively determined by certified graders according to U.S. wool grade standards (Pohle, 1963). Staple length $(\mathrm{cm})$ was measured prior to shearing at midside without stretching the fiber. Staple length was primarily measured on lambs and rams only. Staple lengths for ewe lambs were available from 1977 through 1991. Only wool data from ewes and ewe lambs with lambing records were included in these analyses.

\section{Statistical Analysis}

(Co)variance components for each trait were estimated from single-trait analyses using models described in Table 4. (Co)variance components between traits were estimated from two-trait analyses with the models described in Table 4 combined with appropriate covariances between random effects in the model for the pairs of traits. Breeding values of individual animals were estimated from single-trait analyses and were also estimated from a seven-trait analysis, using the within-trait co(variances) from single-trait analyses and between-trait correlations from two-trait analyses. Means of estimated breeding values by year of birth were calculated from the seven-trait analysis and compared with the corresponding means of estimated breeding values from single-trait analyses.

A derivative-free REML algorithm (DFREML, Graser et al., 1987), using computer programs of Boldman et al. (1995), was used to estimate (co)variance 
Table 1. Number of records, animals with records, sires and dams of animals with records, years of records, and unadjusted means and standard deviations of prolificacy, weight, and wool traits

\begin{tabular}{|c|c|c|c|c|c|c|}
\hline Trait & Records & $\begin{array}{l}\text { Animals with } \\
\text { records }\end{array}$ & Sires & Dams & $\begin{array}{l}\text { Years of } \\
\text { record }\end{array}$ & Mean \pm SD \\
\hline \multicolumn{7}{|l|}{ Prolificacy traits (trait of ewe) } \\
\hline Litter size at weaning $^{\mathrm{a}}$ & 38,625 & 10,367 & 1,381 & 5,302 & $1950-1998$ & $0.97 \pm 0.72$ \\
\hline \multicolumn{7}{|l|}{ Weight traits (trait of lamb) } \\
\hline Birth weight, kg & 33,994 & 33,994 & 1,535 & 8,418 & $1950-1998$ & $4.90 \pm 0.83$ \\
\hline Fleece weight, kg & 36,807 & 10,029 & 1,376 & 5,266 & $1953-1998$ & $4.93 \pm 0.98$ \\
\hline Fleece grade, U.S. spinning count & 36,807 & 10,029 & 1,376 & 5,266 & $1953-1998$ & $60.2 \pm 2.7$ \\
\hline Staple length, $\mathrm{cm}$ & 3,341 & 3,341 & 474 & 1,767 & $1977-1991$ & $8.71 \pm 1.05$ \\
\hline
\end{tabular}

ancludes records from all ewes exposed to a ram at breeding and present at lambing.

components. Local convergence was considered attained when the variance of the -2 log likelihoods in the simplex was less than $10^{-6}$. Global convergence was considered attained when the -2 log likelihoods did not change to the third decimal after restarting.

\section{Single-Trait Analysis}

The single-trait linear model was

$$
\mathbf{y}=\mathbf{X} \boldsymbol{\beta}+\mathbf{Z}_{\mathrm{a}} \mathbf{a}+\mathbf{Z}_{\mathrm{m}} \mathbf{m}+\mathbf{Z}_{\mathrm{p}} \mathbf{p}+\mathbf{e}
$$

where $\mathbf{y}$ is the vector of observations, $\boldsymbol{\beta}$ is the vector of fixed effects, $\mathbf{X}$ is a design matrix relating fixed effects to $\mathbf{y}, \mathbf{a}$ is a vector of additive genetic effects of animals, $\mathbf{m}$ is a vector of maternal genetic effects, $\mathbf{p}$ is a vector of permanent environmental effects corresponding to the ewes, with incidence matrices $\mathbf{Z}_{\mathrm{a}}, \mathbf{Z}_{\mathrm{m}}$, and $\mathbf{Z}_{\mathrm{p}}$ relating the effects to $\mathbf{y}$, and $\mathbf{e}$ is a vector of random residual effects. Nonadditive genetic effects were assumed not to exist.

Expected values and (co)variance structures for random effects were assumed to be:

$\mathrm{E}(\mathbf{y})=\mathbf{X} \boldsymbol{\beta}, \mathrm{E}(\mathbf{a})=\mathrm{E}(\mathbf{m})=\mathrm{E}(\mathbf{p})=0, \operatorname{var}(\mathbf{a})=\mathbf{A} \sigma_{\mathrm{a}}^{2}, \operatorname{var}(\mathbf{m})$ $=\mathbf{A} \sigma_{\mathrm{m}}^{2}, \operatorname{var}(\mathbf{p})=\mathbf{I}_{\mathrm{p}} \sigma_{\mathrm{p}}^{2}, \operatorname{var}(\mathbf{e})=\mathbf{I}_{\mathrm{n}} \sigma_{\mathrm{e}}^{2}, \operatorname{cov}\left(\mathbf{a}, \mathbf{m}^{\prime}\right)=\mathbf{A} \sigma_{\mathrm{am}}$ and $\operatorname{cov}\left(\mathbf{p}, \mathbf{e}^{\prime}\right)=\operatorname{cov}\left(\mathbf{a}, \mathbf{p}^{\prime}\right)=\operatorname{cov}\left(\mathbf{a}, \mathbf{e}^{\prime}\right)=0$

where $\mathbf{A}$ is the numerator relationship matrix, $\mathbf{I}_{\mathrm{p}}$ and $\mathbf{I}_{\mathrm{n}}$ are identity matrices with order equal to the number

Table 2. Number of litters of ewes bred and present at lambing and unadjusted survival rates (percentage of

lambs born) at birth and weaning by type of birth

\begin{tabular}{lrrrr}
\hline \hline & & & \multicolumn{2}{c}{ Survival } \\
\cline { 3 - 5 } Birth type & $\begin{array}{c}\text { Number of litters } \\
\text { (\% of total) }\end{array}$ & Birth & Weaning \\
\hline Nonpregnant & 4,647 & $(12.0)$ & - & - \\
Singles & 17,730 & $(45.9)$ & 90.6 & 77.5 \\
Twins & 15,404 & $(39.9)$ & 95.2 & 73.4 \\
Triplets & 825 & $(2.1)$ & 90.3 & 46.8 \\
Quadruplets & 18 & $(0.1)$ & 83.3 & 38.9 \\
\hline
\end{tabular}

of ewes (p) and number of records (n), and $\sigma_{\mathrm{a}}^{2}, \sigma_{\mathrm{m}}^{2}, \sigma_{\mathrm{p}}^{2}$, and $\sigma_{\mathrm{e}}^{2}$ are the direct additive genetic, maternal additive genetic, permanent environmental, and residual components of variance, respectively, and $\sigma_{\mathrm{am}}$ is the covariance between direct and maternal additive genetic effects. The full model was used for the weight traits, whereas a model with the maternal genetic effects removed was used for the prolificacy and wool traits. A permanent environmental effect was not included in the model for staple length because staple length was recorded only at $1 \mathrm{yr}$ of age.

Fixed effects included in the model for the prolificacy traits were age of ewe in years at lambing ( 1 to 12 ) and year of lambing (1950 to 1998). Records of all ewes that were bred and present at lambing were included. Therefore, number of lambs at birth or at weaning could be zero. Analyses of litter size at birth included only parturitions that resulted from single-sire pen matings. Litter size at weaning included only lambs that resulted from single-sire pen matings that were present with their biological mother at weaning. Models for litter size at weaning included the fixed effect of foster code (1, if the ewe did not raise a foster lamb; 2 , if ewe did raise a foster lamb). Foster lamb records were not included in the record of either the birth dam or the foster dam for litter size at weaning.

The model for birth weight also included the fixed effects of gender of lamb and type of birth (1 to 4), whereas the model for weaning weight included the fixed effects of gender of lamb and type of birth and rearing. One of eight types of birth and rearing combinations was assigned to each lamb to account for a lamb born as a single, twin, triplet, or quadruplet, and reared as a single, twin, or triplet.

Year of production and number of lambs weaned were included as fixed effects in the model for all three wool traits. Because animals could have more than one measurement for fleece weight and fleece grade, the additional fixed effect of age (yr) at shearing was added to the model for these two traits. Julian day of year shorn was included as a linear covariate for all three wool traits. 
Table 3. Number of litters and unadjusted litter sizes of ewes bred and present at lambing and survival rates (percentage of lambs born) at birth

and weaning $(120-\mathrm{d})$ by age of ewe

\begin{tabular}{|c|c|c|c|c|c|c|c|}
\hline \multirow{3}{*}{$\frac{\text { Age, yr }}{1}$} & \multirow{2}{*}{\multicolumn{2}{|c|}{$\begin{array}{c}\text { Number of ewes } \\
(\% \text { of total })\end{array}$}} & \multirow{3}{*}{$\begin{array}{c}\begin{array}{c}\text { Number } \\
\text { of litters }\end{array} \\
2,051\end{array}$} & \multicolumn{2}{|c|}{ Litter size ${ }^{a}$} & \multicolumn{2}{|c|}{ Survival } \\
\hline & & & & \multirow{2}{*}{$\frac{\text { Birth }}{0.55}$} & \multirow{2}{*}{$\frac{\text { Weaning }}{0.32}$} & \multirow{2}{*}{$\frac{\text { Birth }}{90.4}$} & \multirow{2}{*}{$\frac{\text { Weaning }}{61.6}$} \\
\hline & 4,253 & (11.0) & & & & & \\
\hline 2 & 8,829 & (22.9) & 8,018 & 1.15 & 0.83 & 90.7 & 74.0 \\
\hline 3 & 7,448 & (19.3) & 6,934 & 1.40 & 1.05 & 92.0 & 76.3 \\
\hline $4-6$ & 14,103 & $(36.5)$ & 13,292 & 1.56 & 1.18 & 94.0 & 77.1 \\
\hline$\geq 7$ & 3,992 & (10.3) & 3,682 & 1.54 & 1.09 & 94.9 & 73.6 \\
\hline
\end{tabular}

${ }^{\text {a} I n c l u d e s ~ r e c o r d s ~ f r o m ~ a l l ~ e w e s ~ e x p o s e d ~ t o ~ a ~ r a m ~ a t ~ b r e e d i n g ~ a n d ~ p r e s e n t ~ a t ~ l a m b i n g . ~}$

\section{Two-Trait Analyses}

Traits were analyzed by pairs to estimate covariance components. In addition to (co)variance structures for single-trait models, covariances between the two traits depended on the models for the traits (Table 4). For two-trait analyses for litter size at weaning with each of the wool traits, the fixed effect of number of lambs weaned included in the model for wool traits was dropped from the model due to apparent confounding with the litter size weaned trait.

Correlations between permanent environmental effects were estimated between prolificacy traits and wool traits recorded in the same year of production. To estimate environmental correlations between an animal's own birth weight, weaning weight, and yearling staple length and her prolificacy and wool traits, a permanent environmental effect was included in the model for birth weight, weaning weight, and yearling staple length. This assignment of a permanent environmental effect to those traits that were measured only once for each animal was done to force the covariance between environmental effects into the covariance between permanent environmental effects rather than to the covariance between residual effects when one of the traits was measured more than once. Although the environmental covariance across traits can be forced into permanent environmental effects, interpretation requires some caution when one trait, such as birth weight, cannot have repeated measures (Okut et al., 1999). Because of the complete confounding between the permanent environmental and residual effects, variance due to those effects can go to either component of variance, which also makes interpretation of correlations among permanent environmental effects difficult (Bromley et al., 2000). The environmental variance for the single measured trait was calculated by summing variance components for permanent environmental and residual effects. The environmental correlation between traits was calculated with the formula presented by Okut et al. (1999). For pairs of traits measured in the same year for each ewe (litter size at birth, litter size at weaning,

Table 4. Description of fixed and random factors in animal models associated with prolificacy, weight, and wool traits

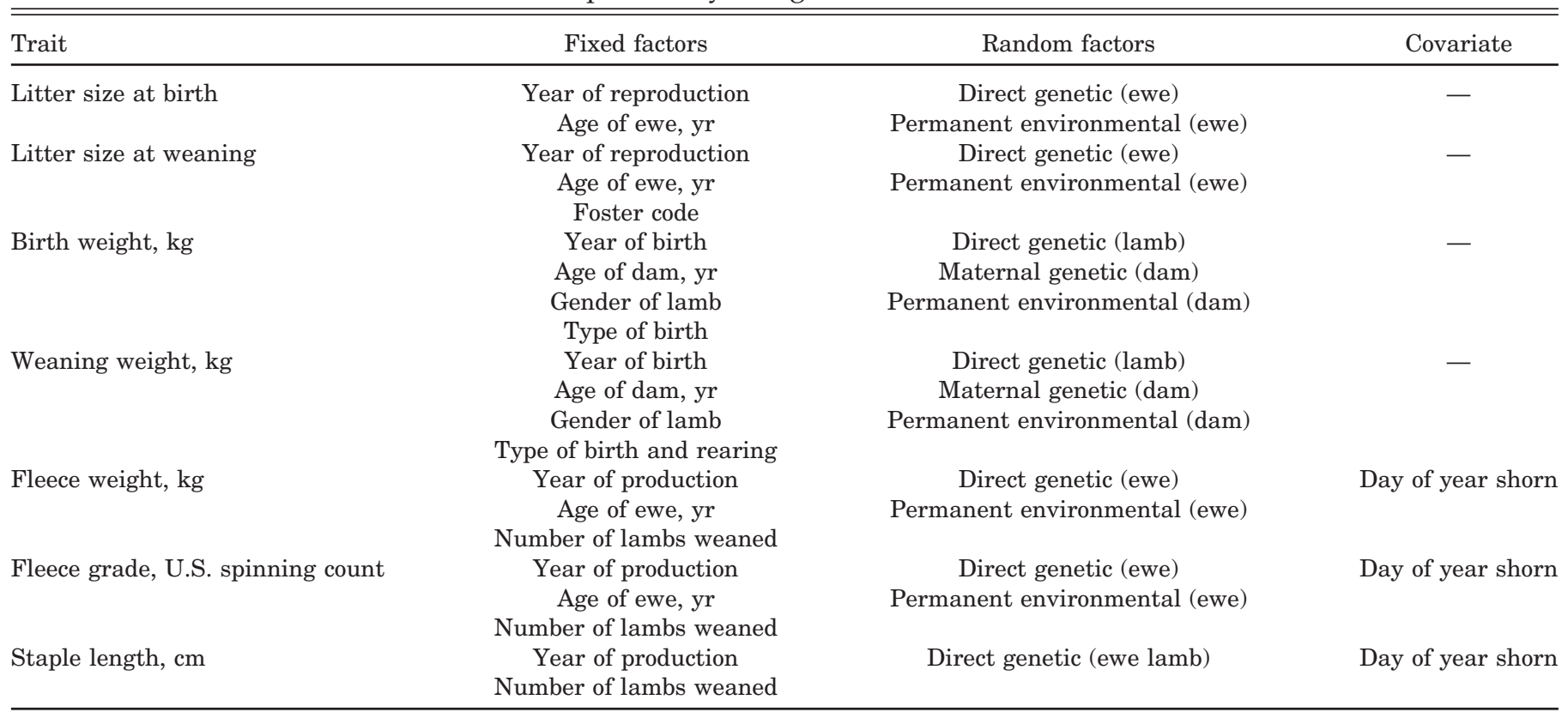


fleece weight, and fleece grade), covariances between both permanent and temporary environmental effects were estimated from bivariate analyses.

\section{Seven-Trait Analysis}

Estimates of (co)variances from single-trait analyses and estimates of correlations from two-trait analyses were used to set up mixed-model equations to estimate breeding values for the seven traits simultaneously. A $9 \times 9$ genetic (co)variance matrix and an $11 \times 11$ environmental (co)variance matrix were constructed. There were two types of permanent environmental covariances between traits included in the environmental (co)variance matrix. The first type was the permanent environmental covariance estimated from traits with repeated records. The second type was where the permanent environmental effect was completely confounded with the temporary environmental (or residual) effect because the trait was measured only once. Because the variance due to the permanent environmental and residual effects can go to either component of variance, a fraction of the total environmental variance $(0.0001)$ was arbitrarily assigned to the residual variance for traits measured only once and the remainder was assigned to the permanent environmental variance.

Each (co)variance matrix had to be adjusted to be positive definite by applying a singular value decomposition to each of the two matrices as follows:

$$
\mathbf{V}=\mathbf{P D P}^{\prime}
$$

where $\mathbf{D}$ is a diagonal matrix of eigenvalues and $\mathbf{P}$ is a matrix of eigenvectors for $\mathbf{V}$ (either the genetic or environmental (co)variance matrix). Any eigenvalue in D that was negative was replaced with a small positive value $(0.0001)$ to create a modified diagonal matrix, $\mathbf{D}^{*}$. A new (co)variance matrix was then calculated as

$$
\mathbf{V}^{*}=\mathbf{P D} * \mathbf{P}^{\prime}
$$

so that $\mathbf{V}^{*}$ is positive definite.

\section{Results and Discussion}

\section{Estimates from Single-Trait Analyses}

Estimates of genetic parameters for prolificacy, weight, and wool traits from single-trait analyses are in Table 5.

Prolificacy Traits. Heritability estimates for the prolificacy traits were small: 0.10 for litter size at birth and 0.07 for litter size at weaning. Fractions of variance due to permanent environmental effects of the ewe were also small: 0.04 for litter size at birth and 0.03 for litter size at weaning. These estimates are similar to those reported for the Columbia breed by Hanford et al. (2002) of 0.09 and 0.06 for heritability for litter size at birth and litter size at weaning and for fractions of variance due to permanent environmental effects of 0.03 for both traits. These estimates are also similar to previously reported estimates for dual-purpose breeds for both litter size at birth and at weaning (Burfening et al., 1993; Fogarty, 1995) and to previously reported estimates for lambs born per parturition and lambs weaned per parturition (de Vries et al., 1998; Sakul et al., 1999; Bromley et al., 2000). The heritability estimate for litter size at weaning is similar to the realized heritability estimate (0.02) for survival to weaning reported by Bradford et al. (1999) for grade Targhee ewes.

Weight Traits. Estimates of direct heritability for both birth weight $(0.25)$ and weaning weight $(0.22)$ were moderate. The estimate of maternal heritability for birth weight was about twice as large as that for weaning weight ( 0.20 vs. 0.11$)$. Estimates of genetic correlation between direct and maternal effects were small for both birth weight $(0.09)$ and weaning weight $(-0.04)$. Variance due to permanent environmental effects associated with the dam as a proportion of total variance was similar for birth weight (0.08) and for weaning weight (0.06). Estimates of both direct and maternal heritability for birth weight were similar to the estimates ( 0.27 and 0.25 , respectively) reported for Columbia sheep by Hanford et al. (2002), whereas our estimates of both direct and maternal heritability for weaning weight were higher than the estimates they reported ( 0.16 and 0.08 , respectively). The estimate of direct heritability for birth weight was in general agreement with the weighted mean of estimates of 0.19 for dual-purpose breeds reported by Fogarty (1995) and the estimate of 0.22 for Targhee sheep reported by Bromley et al. (2000), but was higher than other previously reported estimates ranging from 0.07 to 0.17 (Jurado et al., 1994; Näsholm and Danell, 1996; Gut et al., 2001). The estimate of direct heritability for weaning weight was also in general agreement with the weighted mean of estimates of 0.20 for dual-purpose breeds reported by Fogarty (1995) and the estimate of 0.19 reported by Al-Shorepy and Notter (1996), but was higher than other previously reported estimates of 0.15 for Swedish Finewool sheep by Näsholm and Danell (1996) and 0.16 for Targhee sheep by Bromley et al. (2000). The larger estimate of maternal heritability for birth weight compared with the estimate for weaning weight supports the conclusion of Robison (1981) that maternal genetic effects generally are important for measurements of weight at younger ages and diminish with increasing age. This diminishing maternal genetic effect on lamb weight over time has been reported by others (Al-Shorepy and Notter, 1996; Näsholm and Danell, 1996; Bromley et al., 2000).

Wool Traits. Estimates of direct heritability for wool traits were moderate to large $(0.54,0.41$, and 0.65 , for fleece grade, fleece weight, and staple length, respectively). Estimates of variance due to permanent environmental effects of the ewe as a proportion of total variance were 0.09 for fleece weight and 0.06 for fleece 
Table 5. Estimates of genetic parameters and standard error from single-trait analyses ${ }^{\mathrm{a}}$

\begin{tabular}{|c|c|c|c|c|c|c|}
\hline \multicolumn{7}{|l|}{ Prolificacy traits (trait of ewe) } \\
\hline Litter size at birth & $0.10 \pm 0.01$ & $\mathrm{ND}^{\mathrm{b}}$ & $\mathrm{ND}^{\mathrm{b}}$ & $0.86 \pm 0.01$ & $0.04 \pm 0.01$ & 0.387 \\
\hline \multicolumn{7}{|l|}{ Weight traits (trait of lamb) } \\
\hline Birth weight, kg & $0.25 \pm 0.02$ & $0.20 \pm 0.01$ & $0.09 \pm 0.05$ & $0.45 \pm 0.01$ & $0.08 \pm 0.01$ & 0.475 \\
\hline Weaning weight, $\mathrm{kg}$ & $0.22 \pm 0.02$ & $0.11 \pm 0.01$ & $-0.04 \pm 0.06$ & $0.62 \pm 0.01$ & $0.06 \pm 0.01$ & 25.4 \\
\hline Fleece grade, spinning count & $0.41 \pm 0.01$ & $\mathrm{ND}^{\mathrm{b}}$ & $\mathrm{ND}^{\mathrm{b}}$ & $0.53 \pm 0.01$ & $0.06 \pm 0.01$ & 6.66 \\
\hline Staple length, $\mathrm{cm}$ & $0.65 \pm 0.04$ & $\mathrm{ND}^{\mathrm{b}}$ & $\mathrm{ND}^{\mathrm{b}}$ & $0.35 \pm 0.04$ & $\mathrm{ND}^{\mathrm{c}}$ & 0.920 \\
\hline
\end{tabular}

${ }^{a} h_{a}^{2}=$ direct heritability; $h_{m}^{2}=$ maternal heritability; $r_{a m}=$ correlation between direct and maternal genetic effects; $e^{2}=$ variance due to residual effects as proportion of total variance; $\mathrm{p}^{2}$ = variance due to permanent environmental effects associated with the animal as proportion of total variance, where the animal is the ewe for ewe traits and the dam for lamb traits; $\sigma_{\mathrm{p}}^{2}=$ phenotypic variance.

${ }^{\mathrm{b}}$ Maternal effects not included in the model for traits of the ewe.

${ }^{c}$ Permanent environmental effects not included for staple length because the trait was measured only once at $1 \mathrm{yr}$ of age.

grade. These results are similar to those reported for fleece weight and fleece grade for the Columbia breed by Hanford et al. (2002) of 0.53 and 0.41 for heritability estimates and of 0.14 and 0.11 for fractions of variance due to permanent environmental effects, but larger than the heritability estimate of 0.55 reported for staple length. Heritability estimates for fleece weight and fleece grade agreed with mean estimates of 0.52 and 0.40 , respectively, reported by Bromley et al. (2000). The heritability estimate for staple length was larger than the mean estimate of 0.54 reported by Bromley et al. (2000). The estimate for fleece weight was larger than the weighted mean of 0.36 summarized by Fogarty (1995), but smaller than the 0.66 reported by Saboulard et al. (1995) for clean fleece weight in western whiteface ewes. The estimate for fleece grade was smaller than the weighted mean of 0.52 reported for fiber diameter by Fogarty (1995).

\section{Estimates from Bivariate Analyses}

Estimates of genetic correlations from bivariate analyses between prolificacy, weight, and wool traits are presented in Table 6.

Within Prolificacy Traits. The estimate of direct genetic correlation between litter size at birth and litter size at weaning was large and positive (0.77). The estimate was in good agreement with the estimate of 0.84 reported for the Columbia breed by Hanford et al. (2002). The estimate of genetic correlation was less than the weighted average of 0.91 summarized by Fogarty (1995).

The estimate of correlation between permanent environmental effects of ewes was large and positive for litter size at birth with litter size at weaning (0.73). This estimate was somewhat larger than the estimate of 0.52 for the Columbia breed (Hanford et al., 2002).

Within Weight Traits. The estimate of direct genetic correlation between birth weight and weaning weight was moderate and positive (0.52), in agreement with the estimate of 0.56 for the Columbia breed (Hanford et al., 2002). The estimate was higher than the weighted mean of 0.39 between birth weight and weaning weight summarized by Fogarty (1995). The moderate estimate of direct genetic correlation between birth weight and weaning weight suggests that animals with above-average weaning weight would tend to be above average in genetic merit for birth weight. The estimate of maternal genetic correlation between birth weight and weaning weight was also moderately positive (0.44) and somewhat smaller than the estimate of 0.58 for the Columbia breed (Hanford et al., 2002). The moderately positive maternal genetic correlation indicates that Targhee ewes that are above average in genetic merit for producing lambs with heavier birth weights will tend to produce lambs with heavier weaning weights. Estimates of genetic correlations between direct and maternal effects were both small to moderate (-0.09 and 0.26) and in general agreement with estimates presented by Bromley et al. (2000) and Hanford et al. (2002). The estimate of correlation between permanent environmental effects of the dam for birth and weaning weight was moderately large and positive (0.44) and in agreement with the estimate of 0.46 for the Columbia breed (Hanford et al., 2002).

Within Wool Traits. Estimates of direct genetic correlations between pairs of wool traits were positive between fleece weight and staple length (0.54) and negative between fleece grade and both fleece weight $(-0.47)$ and staple length $(-0.69)$, in agreement with previous estimates (Saboulard et al., 1995; Bromley et al., 2000; Hanford et al., 2002).

The negative (unfavorable) estimate of the genetic correlation between fleece grade and fleece weight was in general agreement with positive (unfavorable) estimates between fleece fiber diameter and fleece weight previously published (Iman et al., 1992; Fogarty, 1995). The negative genetic correlation between fleece weight and grade suggests that selection for fleece weight would decrease genetic merit for fleece grade (increased 
Table 6. Estimates of genetic correlations from bivariate analyses between prolificacy, weight, and wool traits ${ }^{\mathrm{a}}$

\begin{tabular}{|c|c|c|c|c|c|c|c|}
\hline Trait 1 & Trait 2 & $r_{g}$ & $\mathrm{r}_{\mathrm{m}}$ & $\mathrm{r}_{\mathrm{a} 1 \mathrm{~m} 2}$ & $\mathrm{r}_{\mathrm{a} 2 \mathrm{~m} 1}$ & $r_{p}$ & $\mathrm{r}_{\mathrm{e}}$ \\
\hline Litter size at birth & Litter size at weaning & 0.77 & & & & 0.73 & 0.57 \\
\hline Birth weight, kg & Weaning weight, kg & 0.52 & 0.35 & -0.09 & 0.26 & 0.44 & 0.30 \\
\hline Fleece weight, kg & Fleece grade, count & -0.47 & & & & -0.47 & -0.14 \\
\hline Fleece weight, kg & Staple length, cm & 0.54 & & & & $\mathrm{ND}^{\mathrm{b}}$ & 0.15 \\
\hline Fleece grade, count & Staple length, cm & -0.69 & & & & $\mathrm{ND}^{\mathrm{b}}$ & -0.06 \\
\hline Litter size at birth & Birth weight, $\mathrm{kg}$ & 0.00 & & 0.18 & & & 0.03 \\
\hline Litter size at birth & Weaning weight, $\mathrm{kg}$ & 0.20 & & 0.27 & & & 0.07 \\
\hline Litter size at weaning & Birth weight, $\mathrm{kg}$ & 0.00 & & 0.31 & & & 0.01 \\
\hline Litter size at weaning & Weaning weight, $\mathrm{kg}$ & 0.15 & & 0.58 & & & 0.03 \\
\hline Litter size at birth & Fleece weight, kg & -0.19 & & & & 0.47 & -0.12 \\
\hline Litter size at birth & Fleece grade, count & 0.09 & & & & -0.10 & 0.05 \\
\hline Litter size at birth & Staple length, cm & -0.14 & & & & $\mathrm{ND}^{\mathrm{b}}$ & 0.02 \\
\hline Litter size at weaning & Fleece weight, $\mathrm{kg}$ & -0.19 & & & & 0.21 & -0.04 \\
\hline Liter size at weaning & Fleece grade, count & 0.11 & & & & -0.22 & 0.01 \\
\hline Litter size at weaning & Staple length, cm & 0.05 & & & & $\mathrm{ND}^{\mathrm{b}}$ & -0.00 \\
\hline Birth weight, kg & Fleece weight, $\mathrm{kg}$ & 0.24 & & & 0.07 & & 0.17 \\
\hline Birth weight, kg & Fleece grade, count & -0.06 & & & 0.04 & & -0.02 \\
\hline Birth weight, $\mathrm{kg}$ & Staple length, cm & 0.10 & & & -0.09 & & 0.12 \\
\hline Weaning weight, $\mathrm{kg}$ & Fleece weight, $\mathrm{kg}$ & 0.24 & & & 0.02 & & 0.16 \\
\hline Weaning weight, $\mathrm{kg}$ & Fleece grade, count & -0.05 & & & 0.00 & & 0.02 \\
\hline Weaning weight, $\mathrm{kg}$ & Staple length, cm & 0.08 & & & 0.00 & & 0.20 \\
\hline
\end{tabular}

\footnotetext{
${ }^{\mathrm{a}} \mathrm{r}_{\mathrm{g}}=$ correlation between direct genetic effects; $\mathrm{r}_{\mathrm{m}}=$ correlation between maternal genetic effects; $\mathrm{r}_{\mathrm{aimj}}=$ correlation between direct additive genetic effect for trait $i$ and maternal genetic effect for trait $j ; r_{p}=$ correlation between permanent environmental effects (maternal between birth weight and weaning weight and direct between prolificacy and wool traits); $r_{\mathrm{e}}=$ correlation between temporary environmental effects.

${ }^{b}$ Permanent environmental effects not included for staple length because the trait was measured only once at $1 \mathrm{yr}$ of age.
}

fiber diameter). The positive estimate of genetic correlation (0.54) between fleece weight and staple length agreed in direction with the estimate of 0.20 between yearling fleece weight and staple length reported for Merino sheep by Atkins (1997). The positive genetic correlation indicates that staple length would increase as a genetic response to selection for increased fleece weight. Although Atkins (1997) reported a negative (favorable) genetic correlation between yearling fiber diameter and staple length $(-0.10)$, the negative (unfavorable) genetic correlation between fleece grade and staple length estimated in this study indicates that staple length would decrease as a genetic response to an increase in fleece grade (fiber diameter becomes finer).

Prolificacy and Weight Traits. Estimates of genetic correlations among prolificacy and weight traits ranged from 0.00 between both litter size traits and birth weight to 0.20 between litter size at birth and weaning weight, which were in general agreement with estimates presented for the Columbia breed by Hanford et al. (2002). The estimate of the genetic correlation between birth weight and litter size at birth (0.00) was smaller than the average for four breeds $(0.12)$ reported by Bromley et al. (2000) and the average of estimates (0.30) reviewed by Fogarty (1995). The estimate of the genetic correlation between birth weight and litter size at weaning $(0.00)$ was smaller in magnitude than both the average for four breeds $(-0.12)$ reported by Bromley et al. (2000) and the average of estimates (0.34) summarized by Fogarty (1995).
The estimate of genetic correlation between weaning weight and litter size at birth $(0.20)$ was in agreement with the average of estimates $(0.20)$ reported by Fogarty (1995) and with the average for four breeds (0.16) reported by Bromley et al. (2000) for average daily gain to weaning and litter size at birth. Positive correlations suggest selection for weaning weight may increase genetic merit for litter size at birth. The estimate of genetic correlation between weaning weight and litter size at weaning $(0.15)$ was the same as the average for three breeds (Polypay, Rambouillet, and Targhee) reported by Bromley et al. (2000) for average daily gain to weaning and litter size at weaning (0.14), but was substantially different from the estimate they reported for the Columbia breed $(-0.82)$. The estimate was also smaller than the average of estimates (0.34) reported by Fogarty (1995).

Estimates of correlations between direct genetic effects for prolificacy traits and maternal genetic effects for weight traits were moderate to large and in general agreement with the estimates for the Columbia breed (Hanford et al., 2002) and with the average for four breeds reported by Bromley et al. (2000), with the exception of the correlation between litter size at birth and birth weight of -0.11 reported by Bromley et al. (2000).

Prolificacy and Wool Traits. Estimates of genetic correlations between prolificacy traits and wool traits ranged from -0.19 between both litter size traits and fleece weight to 0.11 between litter size at weaning and fleece grade. These estimates were in general 




Figure 1. Means of estimates of breeding value (BV) for litter size at birth by year of birth from single- and seven-trait analyses.

agreement with estimates presented for the Columbia breed by Hanford et al. (2002) and with the average of four breeds reported by Bromley et al. (2000). One exception was between litter size at weaning and staple length (0.05) where both Bromley et al. (2000) and Hanford et al. (2002) reported moderate negative correlations ( -0.33 and -0.20 , respectively). In agreement with conclusions hypothesized by Hanford et al. (2002), small negative correlations between fleece weight and the litter size traits indicate ewes that are genetically predisposed to produce larger litters also tend to produce lighter fleeces.

Weight and Wool Traits. Estimates of genetic correlations ranged from -0.06 between birth weight and fleece grade to 0.24 between either birth or weaning weight and fleece weight and were similar to those reported for the average of four breeds by Bromley et al. (2000) and to those reported for the Columbia breed by Hanford et al. (2002). Positive correlations for fleece weight with birth and weaning weight ( 0.24 for both) suggest that genetic factors influencing animal growth also influence wool growth.

\section{Estimates of Individual Breeding Values and Genetic Change}

Means of estimates of breeding value by year of birth calculated from both single-trait analyses and from the seven-trait analysis are plotted in Figures 1 and 2 for prolificacy traits, in Figures 3 and 4 for weight traits, and in Figures 5 to 7 for wool traits. Means of estimates of breeding value by year are deviations from the means of estimates of breeding value for animals born in 1950 (1977 for staple length).

Prolificacy Traits. Means of estimates of breeding value by year of birth for litter size at birth from the single-trait analysis and the seven-trait analysis were similar from 1950 to 1980 (Figure 1). From 1980 to 1998, average estimates of breeding values from the

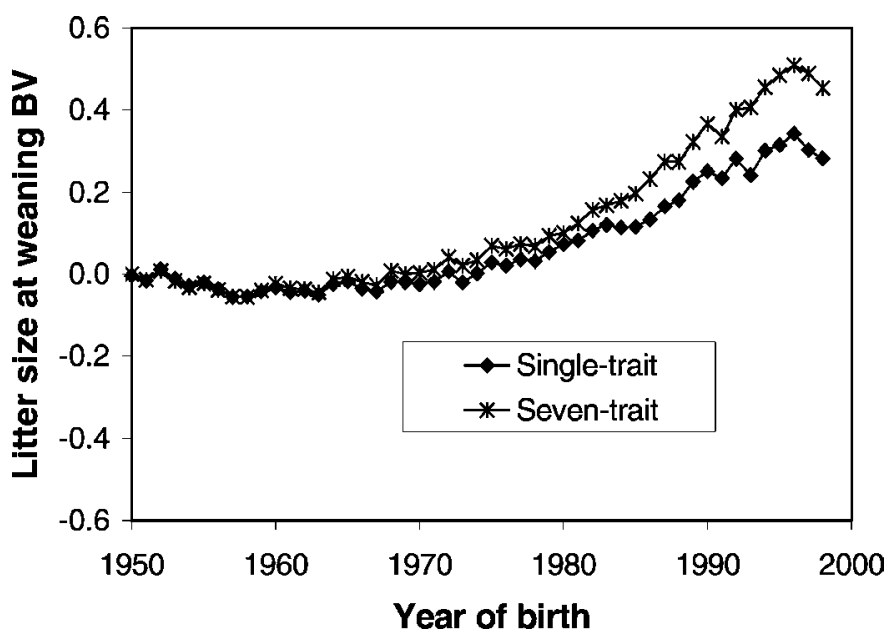

Figure 2. Means of estimates of breeding value (BV) for litter size at weaning by year of birth from singleand seven-trait analyses.

seven-trait analysis increased at a greater rate than average estimates from the single-trait analysis, so that by 1998 , the average estimate of breeding value from the seven-trait analysis was 0.2 lambs greater than that from the single-trait analysis. This difference for litter size at birth may be due to the positive direct correlation for litter size at birth and litter size at weaning (0.77) and the increase of litter size at weaning. The mean estimates for litter size at birth increased about 0.6 lambs from 1950 to 1998 . The plots of the mean estimates of breeding value by year of birth for litter size at birth followed a pattern similar to those from single- and seven-trait analyses for the Columbia breed (Hanford et al., 2002).

Means of estimates of breeding value by year of birth for litter size at weaning from the single- and the seventrait analyses also were similar from 1950 to 1980 (Fig-

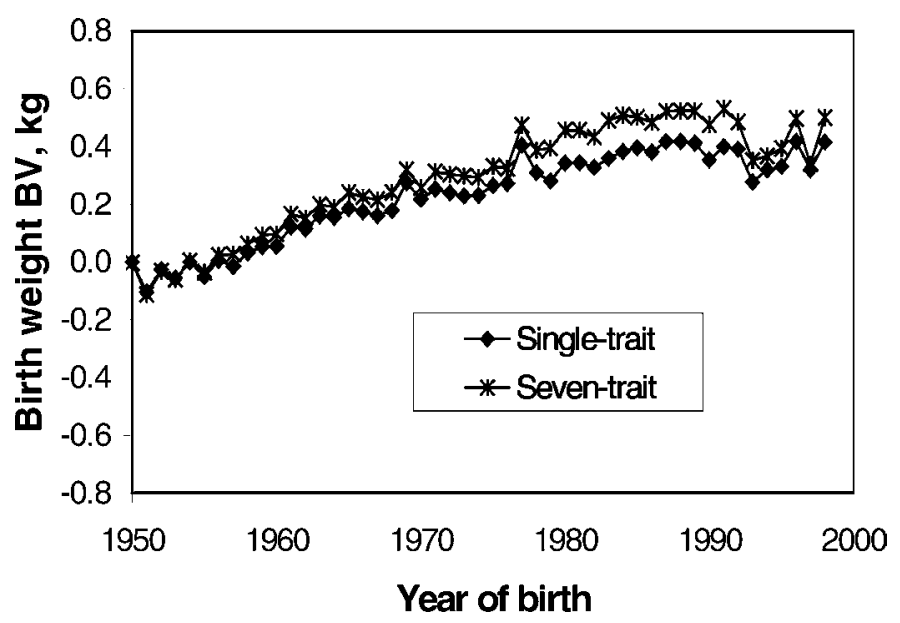

Figure 3. Means of estimates of breeding value (BV) for birth weight of lambs by year of birth from singleand seven-trait analyses. 


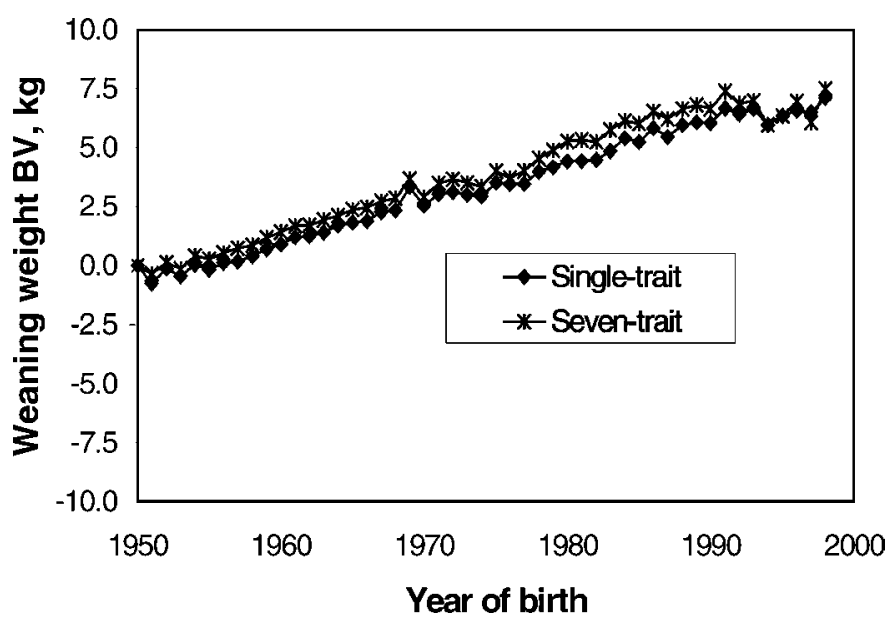

Figure 4. Means of estimates of breeding value (BV) for weaning weight of lambs by year of birth from singleand seven-trait analyses.

ure 2). From 1980 to 1998 , average estimates of breeding values from the seven-trait analysis increased at a greater rate than average estimates from the singletrait analysis, so that by 1998 , the average estimate of breeding value from the seven-trait analysis was 0.2 lambs greater than from the single-trait analysis. As with litter size at birth, this difference for litter size at weaning may be due to the positive direct correlation between the two traits and the increase of litter size at birth. The mean of estimates of breeding value for litter size at weaning increased by 0.4 lambs during the study period, which was less than the increase for litter size at birth. The plots of the mean estimates of breeding value by year of birth for litter size at weaning followed a pattern different from those from single-trait and seven-trait analyses for the Columbia breed (Hanford et al., 2002). For the Columbia breed, the average estimates of breeding value calculated from the single-trait

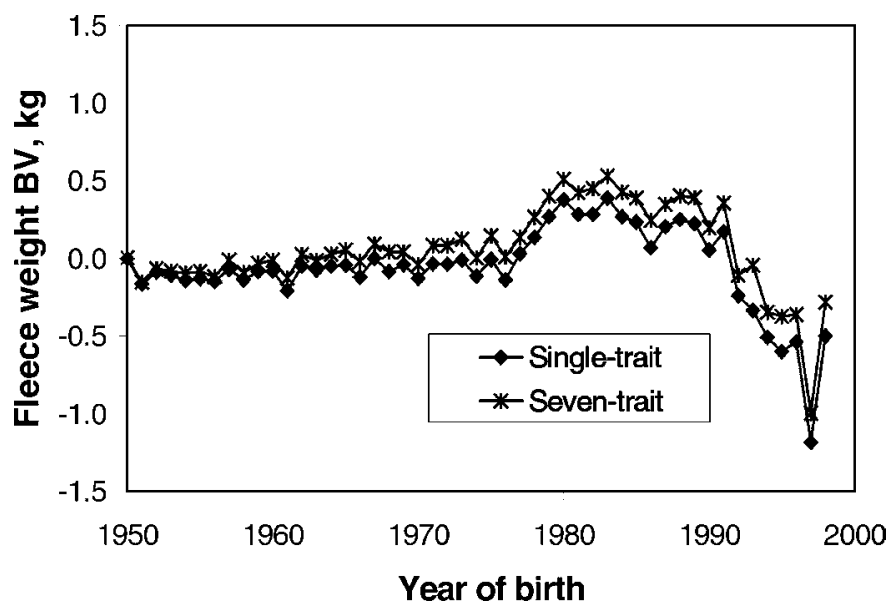

Figure 5. Means of estimates of breeding value (BV) for fleece weight of ewes and ewe lambs by year of birth from single- and seven-trait analyses.

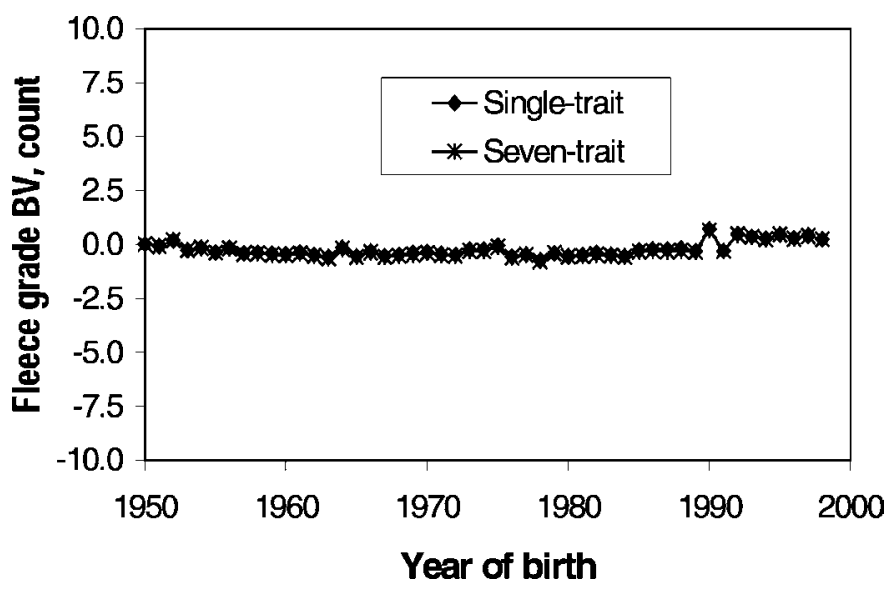

Figure 6. Means of estimates of breeding value (BV) for fleece grade of ewes and ewe lambs by year of birth from single- and seven-trait analyses.

analysis were greater than the average estimates of breeding value calculated from the seven-trait analysis, which was thought to be due partly to the introduction of outside Columbia rams, which negatively impacted weaning weight, which in turn was correlated with litter size at weaning (0.24).

Weight Traits. Means of estimates of breeding value for birth weight by year of birth from the single-trait analysis were slightly less from 1958 to 1976 than means of estimates of breeding value from the seventrait analysis (Figure 3). During that period, the average estimate of breeding value for birth weight increased by $0.3 \mathrm{~kg}$. The mean of estimates of breeding value for birth weight increased more than $0.2 \mathrm{~kg}$ between 1977 and 1978. After 1978, and until 1992, means of estimates of breeding value from the single-trait analysis were about $0.2 \mathrm{~kg}$ less than means of estimates of breeding value from the seven-trait analysis. Selection was not directly applied for birth weight. The 0.2

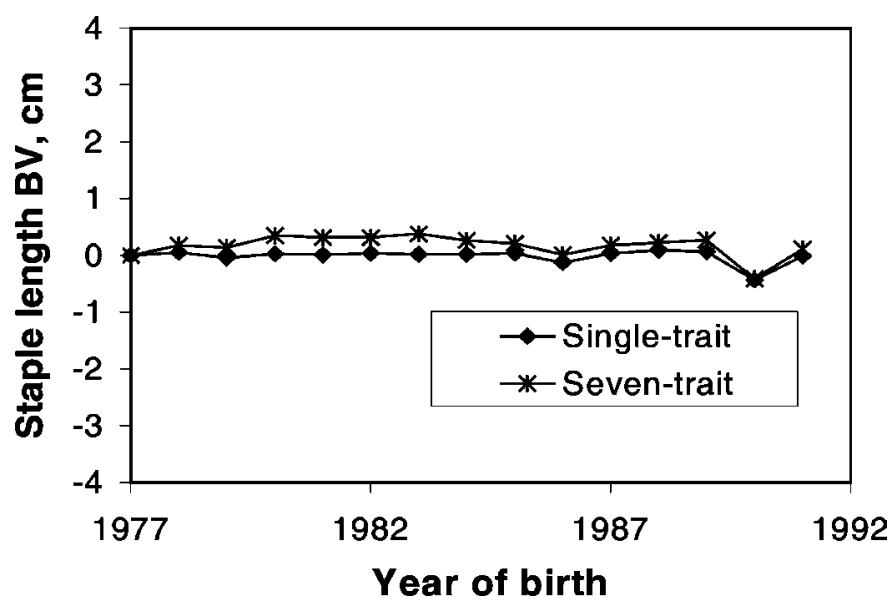

Figure 7. Means of estimates of breeding value (BV) for staple length of ewe lamb fleeces by year of birth from single- and seven-trait analyses by year of birth 
$\mathrm{kg}$ difference between the two means of estimates of breeding value for birth weight may be due to the positive genetic correlations between birth weight and litter size at birth and also weaning weight. The difference between means of estimates of breeding value from single- and seven-trait analyses decreased after 1992. Means of estimates of breeding value for birth weight increased about $0.5 \mathrm{~kg}$ during the study period. The plots of the mean estimates of breeding value by year of birth for birth weight followed a pattern similar to those from single- and seven-trait analyses for the Columbia breed (Hanford et al., 2002).

Means of estimates of breeding value for weaning weight by year of birth from single-trait analysis were slightly less from 1956 to 1977 than means of estimates of breeding value from the seven-trait analysis (Figure 4). During this period, the average estimate of breeding value for weaning weight increased about $4.0 \mathrm{~kg}$. After 1978, and until 1992, means of estimates of breeding value from the single-trait analysis were about $1.0 \mathrm{~kg}$ less than means of estimates of breeding value from the seven-trait analysis. This difference between the two average estimates of breeding value for weaning weight may be due to the positive direct correlation for birth weight and weaning weight $(0.52)$ and the increase of birth weight. During the 49 -yr period, the mean of estimates of breeding value by year of birth for weaning weight increased about $7.5 \mathrm{~kg}$. The plots of the mean estimates of breeding value by year of birth for weaning weight followed a similar pattern to those from single- and seven-trait analyses for the Columbia breed (Hanford et al., 2002).

Wool Traits. Means of estimates of breeding value for fleece weight by year of birth from single- and seventrait analyses showed a fairly consistent pattern with means of estimates from the seven-trait analysis higher than those from the single-trait analysis (Figure 5). The larger means of estimates of breeding value from the seven-trait analysis may be due to the large negative genetic correlation of -0.47 between fleece weight and fleece grade and small positive correlations between fleece weight and both birth (0.24) and weaning weight (0.24). Means of estimates of breeding value for fleece weight did not vary much from the base year from 1954 to 1977 . From 1977 to 1980 , the means of estimates of breeding value increased by $0.5 \mathrm{~kg}$ compared with the base year. Means of estimates of breeding value then were between 0.4 and $0.5 \mathrm{~kg}$ heavier than the base year until about 1991, when means of estimates of breeding value decreased to $1.0 \mathrm{~kg}$ below the base year estimates by 1997, although they rebounded to $0.3 \mathrm{~kg}$ below the base year estimates in 1998. The plots of the mean estimates of breeding value by year of birth for fleece weight followed a pattern similar to those from singletrait and seven-trait analyses for the Columbia breed (Hanford et al., 2002), except that they reported an increase of $0.3 \mathrm{~kg}$ above the base year by the end of the study period.
Means of estimates of breeding value by year of birth for fleece grade were similar between single- and seventrait analyses (Figure 6) and varied less than 1 spinning count from the base year throughout the study period. The plots of the mean estimates of breeding value by year of birth for fleece grade followed a pattern similar to those from single- and seven-trait analyses for the Columbia breed (Hanford et al., 2002).

Means of estimates of breeding value by year of birth for staple length were similar between single- and seven-trait analyses (Figure 7) and differed by less than $0.5 \mathrm{~cm}$ from the base year throughout the study period. The plots of the mean estimates of breeding value by year of birth for staple length followed a different pattern from those values for the Columbia breed (Hanford et al., 2002). For the Columbia breed, the yearly means of breeding values from the seven-trait analysis were greater than those from the single-trait analysis, which was thought to be due to the high correlation between staple length and fleece weight (0.55) and the increase in fleece weight during the study period.

Estimated breeding values averaged over year of birth did not appear to differ substantially between estimates of breeding values obtained from single- and seven-trait analyses, except for traits which were highly correlated with another trait that had responded to selection. Estimates of breeding value for litter size at birth and litter size at weaning from the seven-trait analysis tended to be higher relative to estimates from single-trait analyses, which may be due to the high genetic correlation between them (0.77). Estimates of breeding value for birth weight and weaning weight from the seven-trait analysis also increased relative to estimates from single-trait analyses due to the high genetic correlation between them (0.52). Estimates of genetic correlations less than 0.5 did not have a noticeable impact on means of estimates of breeding value of other traits.

\section{Implications}

The results of this study confirm results of a previous Columbia breed study (Hanford et al., 2002). Litter size at weaning and weaning weight are both components of weaning performance, an economically important trait, but are slightly heritable. However, selection based on weaning performance over a long period could result in a moderate positive response in both litter size at weaning and weaning weight in flocks of dual-purpose breeds, such as the Targhee or Columbia. Although litter size at birth and birth weight are also slightly heritable, positive genetic correlations between components of weaning performance with both of these traits suggest that selecting for weaning performance would result in positive genetic gains in both litter size at birth and birth weight. Because of the low genetic correlations between weaning performance and wool traits, wool traits would not be expected to be adversely af- 
fected over a long period of selection for weaning performance.

\section{Literature Cited}

Al-Shorepy S. A., and D. R. Notter. 1996. Genetic variation and covariation for ewe reproduction, lamb growth, and lamb scrotal circumference in a Fall-lambing sheep flock. J. Anim. Sci. 74:1490-1498.

Atkins, K. D. 1997. Genetic improvement of wool production. Pages 471-504 in The Genetics of Sheep. L. Piper and A. Ruvinsky, ed.

Boldman, K. G., L. A. Kriese, L. D. Van Vleck, C. P. Van Tassell, and S. D. Kachman. 1995. A Manual for the Use of MTDFREML. A set of programs to obtain estimates of variances and covariances [DRAFT]. ARS-USDA, Clay Center, NE.

Bradford G. E., H. Sakul, and M. R. Dally. 1999. Selection for weaning weight or litter size in range sheep: II. Correlated responses and effect on productivity. Sheep Goat Res. J. 15:138-146.

Bromley, C. M., G. D. Snowder, and L. D. Van Vleck. 2000. Genetic parameters among growth, prolificacy, and wool traits of Columbia, Polypay, Rambouillet, and Targhee sheep. J. Anim. Sci. 78:846-858.

Burfening, P. J., S. D. Kachman, K. J. Hanford, and D. Rossi. 1993. Selection for reproductive rate in Rambouillet sheep: Estimated genetic change in reproductive rate. Small Rumin. Res. 10:317-330.

de Vries, M. J., E. H. van der Waaij, and J. A. M. van Arendonk. 1998. Estimation of genetic parameters for litter size in sheep: A comparison of a repeatability and a multivariate model. Anim. Sci. 66:685-688.

Ercanbrack, S. K., and A. D. Knight. 1981. Weaning trait comparisons among inbred lines and selected noninbred and randomly bred control groups of Rambouillet, Targhee, and Columbia sheep. J. Anim. Sci. 52:977-988.

Ercanbrack, S. K., and A. D. Knight. 1998. Responses to various selection protocols for lamb production in Rambouillet, Targhee, Columbia, and Polypay Sheep. J. Anim. Sci. 76:1311-1325.

Fogarty, N. M. 1995. Genetic parameters for live weight, fat and muscle measurements, wool production and reproduction in sheep: A review. Anim. Breed. 63:101-143. (Abstr.)
Graser, H.-U., S. P. Smith, and B. Tier. 1987. A derivative-free approach for estimating variance components in animal models by restricted maximum likelihood. J. Anim. Sci. 64:1362-1370.

Gut, A., P. Ślósarz, and T. Szwaczkowski. 2001. Genetic trends of some performance traits in Whiteheaded Mutton sheep. Czech. J. Anim. Sci. 46:363-369.

Hanford, K. J., L. D. Van Vleck, and G. D. Snowder. 2002. Estimates of genetic parameters and genetic change for reproduction, weight, and wool characteristics of Columbia sheep. J. Anim. Sci. 80:3086-3098.

Iman, N. Y., C. L. Johnson, W. C. Russell, and R. H. Stobart. 1992. Estimation of genetic parameters for wool fiber diameter measures. J. Anim. Sci. 70:1110-1115.

Jurado, J. J., A. Alonso, and R. Alenda. 1994. Selection response for growth in a Spanish Merino flock. J. Anim. Sci. 72:1433-1440.

Lasslo, L. L., G. E. Bradford, D. T. Torell, and B. W. Kennedy. 1985. Selection for weaning weight in Targhee sheep in two environments. I. Direct response. J. Anim. Sci. 61:376-386.

Näsholm, A., and Ö. Danell. 1996. Genetic relationships of lamb weight, maternal ability, and mature ewe weight in Swedish finewool sheep. J. Anim. Sci. 74:329-339.

Okut, H., C. M. Bromley, L. D. Van Vleck, and G. D. Snowder. 1999. Genotypic expression at different ages: I. Prolificacy traits of sheep. J. Anim. Sci. 77:2357-2365.

Pohle, E. M. 1963. Grading and production of wool. Pages 547-615 in Wool Handbook. W. von Bergen, ed. John Wiley \& Sons, New York.

Robison, O. W. 1981. The influence of maternal genetic effects on the efficiency of selection-A review. Livest. Prod. Sci. 8:121-137.

Saboulard, M., W. C. Russell, and M. L. Riley. 1995. Selection for lambing rate and clean fleece weight in sheep. J. Anim. Sci. 73:3195-3198.

Sakul, H., G. E. Bradford, and M. R. Dally. 1999. Selection for litter size or weaning weight in range sheep: I. Selection practiced and direct response. Sheep Goat Res. J. 15:126-137.

Snowder, G. D., A. D. Knight, L. D. Van Vleck, C. M. Bromley, and T. R. Kellom. 2001. Usefulness of subjective ovine milk scores. I. Associations with range ewe characteristics and lamb production. J. Anim. Sci. 79:811-818.

Terrill, C. E. 1947. Breed crosses used in the development of Targhee sheep. J. Anim. Sci. 6:83-92. 